\title{
Teaching and Learning: An Overview of the Thematic Section [Overview Paper]
}

\author{
Manja Klemenčič and Paul Ashwin
}

Higher education institutions today operate in a rapidly changing environment and this is undoubtedly reflected in their core functions of teaching and learning. Teaching and learning in higher education are influenced by a well-rehearsed set of global trends such as the changing demography of student populations and higher participation of non-traditional students; growing global interconnectedness and the proliferation of digital media; and an increasing market orientation in higher education.

Other, perhaps more controversial, debates in contemporary higher education revolve around the question of standardization of assessment of institutional performance, including standardized evidence to demonstrate how much students are actually learning. STEM subjects are hailed for their service to innovative knowledge economies, leaving open the question of how to balance resources between the different disciplines and the relative prestige of different fields of study. There is concern among some educators that students are becoming too instrumental in their orientation to their degrees, preferring vocational and professional training over a more knowledge-focused higher education. The cost of higher education is rising everywhere and most of the countries and institutions are questioning the sustainability of higher education financing; many indeed are exploring on-line learning as possible way to cut costs (of teaching) or create revenue or both.

It is within this environment that we examine teaching and learning in higher education, in order to explore what we know and how to move forward. European cooperation to advance teaching and learning has been fragmented and lacked an

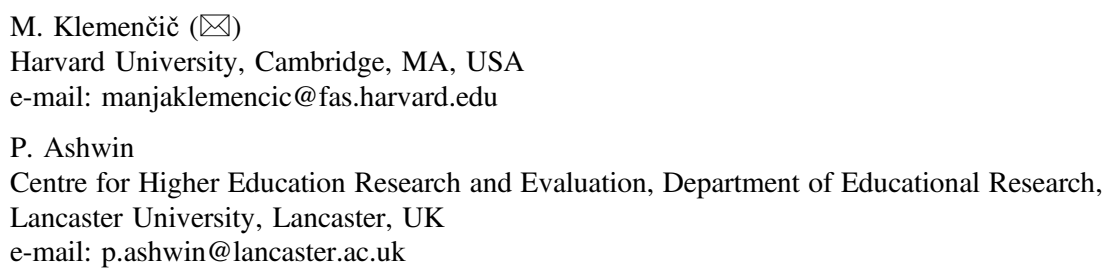


overarching strategy. At the level of national policy, there appears to be unevenness in teaching and learning initiatives among European governments. For example, there are only a few countries that have a national body devoted to advancement of basic and applied research related to teaching and learning (the Higher Education Academy in the UK and the new Higher Education Authority in Sweden are among the few such examples). Many countries have no national strategy on teaching and learning in higher education, and advancements in this area are left to individual institutions to formulate and fund. Some institutions have centres for advancement of teaching and learning, which support inter-institutional collaboration in development and assessment of innovative pedagogies, educational technologies, and curricula, and in research in the learning processes. In many institutions, teachers in higher education tend to be evaluated by their students, but are then left to their own devices to self-improve (or not). Given the rapidly changing environment for teaching and learning outlined above, we argue that a more coordinated and systematic approach is needed to support the development of teaching and learning in higher education in Europe.

\section{Tensions in the Scholarship on Teaching and Learning and Emerging Research Agendas}

In this section, we will consider the current scholarship on teaching and learning in higher education. Rather than providing a comprehensive review of the scholarly findings in this broad and multidisciplinary field of research, we will examine key tensions in this field. We take this approach because we see these tensions as highlighting important conflicts of what is valued, and we want to highlight the ways in which both sides of each tension have something important to tell us about teaching and learning in higher education. Rather than suggesting that these tensions can be resolved, this approach allows us to emphasise the importance of taking a multiplicity of perspectives to understand teaching and learning in higher education (see Ashwin 2009 for further discussion of this approach).

The scholarship of teaching and learning is conducted within and across several fields (e.g. psychology, sociology, educational sciences, public policy, etc.). The levels of analysis include individual and interpersonal, as well as institutional (classroom, study programme, entire higher education institutions or their subunits) and systemic (national higher education systems or international and comparative approaches). It is between these different approaches and levels of analysis that we can see key tensions arising that highlight important issues about teaching and learning in higher education. We examine three of these: the tension between a focus on individual student learning and the institutional contexts in which they learn; the tension between the assessment of standardized outcomes and the assessment of students' individual achievements; and the tension between institutional performance and institutional quality. 
Understanding student learning and development has, for a long time, been a domain of psychological strand in educational research. A large body of research has examined the ways in which students learn and the factors that lead to high quality learning outcomes (Biggs and Tang 2011; Entwistle 2009; Kolb 1984; Tinto 1975). This research has also explored the connection between learning and self-regulation in higher education (Zimmerman and Campillo 2002), and motivation as an essential dimension of self-regulated learning (Zimmerman and Campillo 2002; Zimmerman and Schunk 2001). The basic proposition in this literature is that learning takes place in a system of reciprocal causal relations between students' unique personal characteristics, such as cognitive skills, and emotional dispositions, and environmental factors, which come directly from the educational environment, as well as from broader context including socio-economic background, former educational opportunities and achievements, various support systems (from parents, peers, school, etc.). Whilst the impact of the educational environment is recognized, the main focus is on the ways in which students take charge of their own learning processes. For example, the theoretical model by Zimmerman (2002) includes three distinct phases and their underlying self-regulatory processes which are then cyclically repeated as student approaches learning tasks. The forethought phase includes task analysis and self-motivation beliefs (such as outcome expectation, self-efficacy and goal-orientation). Performance phase includes self-control (including time management, help-seeking, etc.) and self-observation (metacognitive monitoring). The self-reflection phase contains self-judgment and self-reaction, both of which then feed again into the forethought phase of another or simultaneous learning process.

On the other side of this tension is the sociological literature which has over the last twenty years focused on the influence of the educational programs and extracurricular life along with the broader institutional characteristics on student learning and development (Pascarella and Terenzini 1991, 2005). This literature draws a causal link between student engagement in educationally-purposeful activities and student learning, retention and success in higher education (Astin 1993; Kuh 2001, 2003, 2005; Kuh et al. 2005, 2010). The argument goes that almost any type of student involvement in college positively affects student learning and development (Astin 1993). The sociological literature is based on the premise that higher education institutions shape student development, both in terms of knowledge and skills, but also their values and attitudes. Hence, specific institutional interventions are sought to improve the effects of institutions and programmes on student learning and development. Sociological literature on the effects of higher education on students unravels the contextual factors in student learning which go beyond the classroom or even campus environment. They try to capture students' socioeconomic background and the different capitals (cultural, social, and financial) students possess, as well as developments and norms in the broader socio-economic and cultural environment in which higher education is embedded. This research opens a way to the questions of what higher education is for, the desired learning outcomes, and how to prepare students not only for their future professions (and often multiple, highly diverse - in location and in discipline or sector-professions), but also 
citizenship, creative, innovative and ethical agency within any given context of their professional and personal lives. The focus of this research is not only on individual students, and their educational experience in higher education institution, but also the broader society and the connection between higher education, student learning and development, and broader societal and economic development. The questions of student retention and learning of non-traditional students are some of the important areas of research here.

Clearly both sides of this tension are important. We both need to know how students can become active agents of their own learning and the ways in which their institutions structure their educational experiences. A focus on one side or other of this tension, either leads us to underplay the role of higher education institutions in shaping students' experiences or to portray students as passive consumers of their education, who simply follow the paths laid down by their institutions.

A similar tension is in evidence in broader discussions on curricular reforms including defining student learning outcomes and determining qualification frameworks (see Tremblay et al. 2012 for more information). This tension is around the extent to which student learning outcomes and the assessment of learning outcomes can be standardised across national and disciplinary boundaries and the extent to which they should reflect the particular and authentic achievements of individual students. There are strong pressures for standardisation in order to allow the measurement of the performance and efficiency of higher education institutions, and to ensure equitable higher education for all students regardless of which institution they study in. The legitimacy of these demands needs to be recognised as governments and increasingly students pay for higher education, and scholars interested in human capital development (in the sense of accumulated knowledge, skills, expertise by higher education graduates) have begun to explore the questions of the expected student learning outcomes in higher education. One key question here is how we can measure learning outcomes in higher education. Another question is how learning outcomes can be transposed into various economic and social benefits towards improving productivity in market activities, increase in economic growth, active citizenship, civilizational advancement through arts and culture and advancements in health, family welfare, safety, etc. The direct contribution of higher education to the knowledge economies and knowledge societies has been brought to the fore in policy, and consequently also shapes the research agenda.

On the other side of this tension, is the view that what is higher about higher education is the personal relationship that students develop with disciplinary and professional knowledge. It is this which provides the transformative aspects of higher education that is so highly valued by students, governments and societies. Thus if standardisation leads to a focus on identifying outcomes that are measurable across contexts rather than outcomes that reflect students' individual transformation, then the danger is that we lose more than we gain. Again, we are not suggesting a resolution to this tension, but highlighting the mutual importance of learning outcomes being meaningful to those outside higher education, whilst also reflecting the personal transformation that is emblematic of a higher education. Keeping this tension in mind is particularly important in the face of the rapidly 
evolving teaching, learning and assessment context in higher education. The experimentation with teaching technologies, including the significant investment in massive open online courses (MOOCs), is rapidly changing the traditional approaches to teaching and learning, broadening the dissemination of teaching or widening access to learning, and also enabling research into teaching and learning. Inevitably, teaching technology will, in one way or another, mark the future of research in teaching and learning, but we need to consider how the tension between standardisation and individual transformation is played out through these technologies.

The discussion of what is measured brings us to the final tension we will examine, that between institutional performance and institutional quality. We have been witnessing evolution in governance of higher education institutions and in governmental steering. Research in public policy and organizational studies poses the question of mechanisms and instruments to develop teaching and learning at institutional and system levels. On one side of this tension we have the demand for reliable and valid data in order to measure the performance of higher education institutions. On the other side of this tension, we have a focus on the quality of educational processes within higher education institutions, beyond their performance on measures that can often reflect how well institutions play the "quality game' as much as they reflect the quality of education provided. If a focus on institutional performance leads to the valuing of what is measurable rather than measuring what is valuable, then the danger is that there is a dislocation between the performance of institutions on national and international indicators and the quality of educational experience offered to students (see Ashwin et al. 2012 for one example of this). In the face of this tension it is important to bear in mind the usefulness of the information provided by performance measures but also to recognise that it offers only a partial picture of what is happening. Without such information we lose an insight into what is happening in universities, but if we engage with it uncritically then it will obscure more than it will reveal about students experiences of teaching and learning in higher education.

In summary, teaching and learning is a broad field and comprises a number of areas with fast evolving research agendas. We have argued that an awareness of the tensions inherent in this research is important in order to develop a critical understanding of what this research can tell us. This is particularly important because changes in the higher education environment are outpacing advances in scholarship, policy reforms and institutional practice.

\section{Introducing the Chapters}

The chapters in this section nicely illustrate the three tensions that we have outlined above. In her chapter, Sin examines the policy initiatives on teaching and learning that have been developed within the European Higher Education Area. Based on an analysis of Bologna Process policy documents and key reports from supra-national 
actors, Sin examines how policy objectives relating to teaching and learning have moved from the margins to the core of the Bologna Process. Sin attributes this development to the explicit emphasis made in the policies on the higher education sector meeting its economic mission through the production of employable and entrepreneurial graduates. Sin charts the changing focus on teaching and learning within the Bologna Process from a concern with the structure of programmes, to a focus on the importance of student-centred learning, to a focus on curricular reform and finally to a focus on the importance of having university teachers who have been trained as teachers. What is obvious from Sin's chapter is that an overarching policy on modernisation of teaching and learning has not yet been developed, but that initial expert reports have been released by the European Union and OECD which point to such development and restate the need for international collaboration in this area. Furthermore, the predominant frame in the existing policies remains student-centred learning, which is not fully congruent with the growing scholarship on student engagement which advocates for more comprehensive approaches to student learning and development in higher education.

In several European countries, student engagement has already been introduced as a policy objective, and many other countries and institutions consider its use. Student engagement has tended to be embraced by a variety of stakeholders as unquestionably positive, which highlights the ways in which their meaning can shift according to who uses them and the contexts in which they are used. In their chapter, Ashwin and McVitty argue that student engagement indeed has many meanings. They suggest that by analyzing the focus and degree of student engagement, it is possible to address the problems associated with the apparent vagueness of the concept. By examining both what students are being engaged in forming and the degree of engagement that is being sought, we can come to a better understanding about what is intended and what are the likely effects of student engagement. Their approach brings a much needed clarity in the use of the concept both in scholarship and especially in policy; as it highlights both that more engagement is not necessarily better and that higher education is fundamentally about knowledge. They conclude by arguing that it is students and academics collective engagement with disciplinary and professional knowledge that is the basis on which students develop understanding, on which curricula are formed and on which higher education communities are developed.

Levels of student engagement have been increasingly examined through the use of student surveys. In their chapter Klemenčič and Chirikov examine the ways in which student surveys have been used as a primary data source for assessing the quality of learning and teaching in higher education. They examine the policy contexts in which student survey research has proliferated and offer an overview of the most influential student survey designs and their limitations. They argue that student surveys can serve as a helpful screening instrument to assess institutional practice, but there are a number of limitations which call for caution in their use. They argue that technological advances and student use of social media offer the opportunity to adapt qualitative methods of data collection to digital use, which will in turn yield more contextualized data on students in large volumes and at high 
velocity. Such approaches, they suggest, would help to directly meet the needs of institutional decision makers and policy makers.

As well as offering new ways of eliciting student feedback, new technologies have the potential to have an even more fundamental effect on teaching and learning interactions in higher education. In their chapter, Charlier, Cosnefroy, Jézégou and Lameul examine the factors that shape the quality of learning in digital learning environments, and the further research that is needed in order to further develop our understanding of the ways in which students engage with these environments. They argue that in order to understand the quality of learning environments, we need to examine the individual characteristics of the students who are learning within them, how these relate to the characteristics of the digital learning environment, the ways in which the students and the digital environments interact with each other, and the learning outcomes that students achieve through their engagement with the environment.

The assessment of learning outcomes is the focus of the chapter by Coates. He argues that, despite the importance of assessment outcomes in providing essential information about what people have gained through their engagement with higher education, assessment practices have remained largely unchanged for a very long time. As such, Coates argues that assessment is the final frontier in higher education and examines the barriers to the transformation of assessment practices. These include the lack of training of academic staff in assessment and the lack of a professional assessment community. In order to transform assessment, Coates argues that there is a need to embrace new technologies and for changes to institutional management. He also argues that it is likely to require external intervention, either through policy instruments or the involvement of commercial enterprises in assessment practices. These are clearly radical and controversial proposals, which would fundamentally alter assessment's relationship with teaching and learning processes in higher education. Where one stands on these issues will be informed by one's position on the purposes of higher education, and the relative importance of the development of student understanding versus the certification of this understanding that we discussed earlier. Assessment of student learning is certainly an area where no easy solution exists and further research and policy discussions into the matter are needed.

An important purpose of higher education is the inclusion of non-traditional students in a university education. In their chapter, Stănescu, Iorga, González Monteagudo and Freda examine an approach to involving non-traditional students in higher education. They carefully define non-traditional students and argue that an approach focusing on the Narrative Mediation Path (NMP) can support these students in making their transition to higher education. They present an evaluative study of the NMP that, they argue, suggests that it supports students in developing their reflexive competence during a formative experience which enables them to better adjust to their university context. They argue that the changes in the meanings that students attached to their university life involved a closer sense of social connectedness and a reduced sense of alienation, isolation and vulnerability in the face of the academic challenges. 
As a whole, these chapters highlight the rich complexity of teaching and learning interactions in higher education. The different chapters are based on differing views of the purposes of higher education and about what is central to offering students a high quality higher education. Whilst developing evidence-informed policies in relation to teaching and learning is of crucial importance, these differences show how evidence cannot remove the need for judgment that is based on particular values and priorities. This is the case whether it involves the judgment of policy makers in thinking about how to support national systems of higher education, university managers in developing institutional approaches to teaching and learning, university teachers in thinking about how to make particular forms of knowledge and practices accessible to particular groups of students, or students in examining how to make best use of the opportunities they are offered through their engagement in higher education. While the chapters here depict the advances in research into teaching and learning in higher education, they also are a powerful reminder of the potential, indeed a need, for further discoveries in research into higher education.

\section{Recommendations to the Policy Makers}

\subsection{Findings}

- Changes to the demography of student population and high participation of non-traditional students in mass higher education, growing global interconnectedness, development of educational technology and proliferation of digital media, and increasing competition in higher education, all have profound implications on teaching and learning. The changes in the higher education environment are outpacing advances in scholarship, policy reforms and institutional practice. Much of teaching and learning in European classrooms happens without taking into the account the latest scholarship in this area or the changes in the student body and the higher education environment.

- Teaching and learning is a broad field and comprises a number of areas with fast evolving research agendas. Some basic questions as to who are today's students, how do they learn, what motivates them, how do we know what they learn, etc. have still not been satisfactorily resolved.

- There is unevenness in policy initiatives and structural support for advancement of teaching and learning in higher education in Europe. Some countries have no policies and instruments to support teaching and learning.

- The differences between individual institutions are significant in terms of their structures and processes for excellence in teaching and learning. It is not uncommon that higher education teachers are left fully to their own devices to improve their teaching (or not).

- The European cooperation to modernise teaching and learning in higher education has so far been fragmented and in absence of an overarching strategy. 


\subsection{Recommendations}

- Concerted effort is needed among European governments and higher education stakeholders, including higher education researchers, to advance excellence in teaching and learning in European higher education.

- Cross-country exchange of knowledge and collaborative projects for advancement of scholarship in teaching and learning is called for, especially in the following areas:

- Instructional methods, tools and technologies and learning environments (active and effective learning; reflective learning and teaching; educational technology; digital learning environments and online education)

- Authentic assessment of student learning and student experience (consequences of different grading and assessment practices on student learning; standardised versus individualised practices of assessment; student surveys and qualitative methods to investigate student learning and experience)

- Student motivation, self-regulation and student engagement (self-regulated learning; sense of belonging and ownership; student learning outside academic tasks; student engagement in extracurricular activities; student social networks; challenges for non-traditional students)

- Joint initiatives within the EHEA are needed to help translate scholarship into policy and practice through joint policy development, policy learning, and support for capacity-building for research, education and training in the area of teaching and learning at European, national and institutional levels (teaching and learning institutes/agencies/research groups, and institutional units for excellence in teaching and learning).

Open Access This chapter is distributed under the terms of the Creative Commons Attribution Noncommercial License, which permits any noncommercial use, distribution, and reproduction in any medium, provided the original author(s) and source are credited.

\section{References}

Ashwin, P. (2009). Analysing teaching-learning interactions in higher education: Accounting for structure and agency. London: Continuum.

Ashwin, P., McLean, M., \& Abbas, A. (2012). Quality and inequality in undergraduate courses: A guide for national and institutional policy makers. Retrieved from http://www.research.lancs. ac.uk/portal/services/downloadRegister/15790610/Education_brochure_21.03.12.pdf

Astin, A. W. (1993). What matters in college: Four critical years revisited. San Francisco: Jossey-Bass.

Biggs, J., \& Tang, C. (2011). Teaching for quality learning at university: What the student does (4th ed.). Maidenhead Open University Press and Society for Research into Higher Education.

Entwistle, N. (2009). Teaching for understanding at university: Deep approaches and distinctive ways of thinking. Basingstoke: Palgrave Macmillan. 
Kolb, D. (1984). Experiential learning. Englewood Cliffs, New Jersey: Prentice-Hall.

Kuh, G. D. (2001). Assessing what really matters to student learning: Inside the national survey of student engagement. Change, 33(3), 10-17. 66.

Kuh, G. D. (2003). What we're learning about student engagement from NSSE. Change, 35(2), 24-32.

Kuh, G. D. (2005). 7 steps for taking student learning seriously. Trusteeship, 13(3), 20-24.

Kuh, G. D., Kinzie, J., Schuh, J. H., \& Whitt, E. J. (2005). Assessing conditions to enhance educational effectiveness: The inventory for student engagement and success. San Franciscos: Jossey-Bas.

Kuh, G. D., Kinzie, J., Schuh, J. H., Whitt, E. J., \& Associates. (2010). Student success in college: Creating conditions that matter. San Francisco: Jossey-Bass.

Pascarella, E. T., \& Terenzini, P. T. (1991). How college affects students: Findings and insights from twenty years of research. San Francisco: Jossey-Bass.

Pascarella, E. T., \& Terenzini, P. T. (2005). How college affects students (Vol. 2): A third decade of research. San Francisco, CA: Jossey-Bass.

Tinto, V. (1975). Dropout from higher education: A theoretical synthesis of recent research. Review of Educational Research, 45(1), 89-125.

Tremblay, K., Lalancette, D., \& Roseveare, D. (2012). Assessment of higher education learning outcomes. Feasibility study report. Volume 1-Design and implementation. Paris: OECD.

Zimmerman, B. J. (2002). Becoming a self-regulated learner: An overview. Theory Into Practice, 41(2), 64-70.

Zimmerman, B. J., \& Campillo, M. (2002). Motivating self-regulated problem solvers. In J. E. Davidson \& R. Sternberg (Eds.), The nature of problem solving (pp. 233-262). New York: Cambridge University Press.

Zimmerman, B. J., \& Schunk, D. H. (Eds.). (2001). Self-regulated learning and academic achievement: Theoretical perspectives (2nd ed.). Mahwah, NJ: Erlbaum. 